\title{
Herne-ohrakasvustosta säilörehua lypsylehmille
}

\author{
Pirjo Pursiainen, Mikko Tuori, Virgo Karp ja Anna-Riitta Leinonen \\ Kotieläintieteen laitos/Kotieläinten ravitsemustiede, $P L \quad 28,00014$ Helsingin \\ yliopisto, etunimi.sukunimi@helsinki.fi
}

\section{Johdanto}

Puhtaan kokoviljasäilörehun heikkoutena on nurmisäilörehuun verrattuna huonompi sulavuus ja alhainen valkuaispitoisuus. Lisäksi kokoviljasäilörehun tuotantovaikutus voi vuosittain vaihdella suurestikin oljen osuudesta riippuen. Kokoviljasäilörehun ruokinnallista arvoa voidaan kuitenkin parantaa viljelemällä palkoviljoja seoksena yhdessä viljan kanssa. Palkoviljat sekä parantavat rehun sulavuutta että lisäävät sen valkuaispitoisuutta (Mustafa ym. 2000). Palkokasvien viljely vähentää myös typpilannoitustarvetta. Kokoviljasäilörehun ja nurmisäilörehun seoksesta lypsylehmien ruokinnassa on saatu myönteisiä tutkimustuloksia. Sen sijaan palkoviljojen ja vilja-palkoviljaseosten säilönnästä tilamittakaavassa sekä soveltuudesta lypsylehmien ruokintaan tarvitaan lisää tietoa. Tässä tutkimuksessa verrattiin herne-ohrasäilörehua puhtaaseen nurmisäilörehuun lypsylehmien ruokinnassa.

\section{Aineisto ja menetelmät}

Tutkimus tehtiin tammi-huhtikuussa 2003 Viikin opetus- ja tutkimustilan navetassa. Koerehuna oli herneen (lajike Perttu) ja ohran (lajike Mette) seoskasvustosta 23.-24.7.2002 pyöröpaalattu säilörehu. Säilöntäaineena oli AIV2000-liuos (muurahaishappo $55 \%$, ammoniumformiaatti $24 \%$, propionihappo $5 \%$, etyylibentsoaatti $1 \%$, bentsoehappo $1 \%$ ) annosteltuna $51 /$ tn tuoretta rehua. Lisäksi säilöntäainevertailua varten säilöttiin kuusi paalia Feedtech ${ }^{\circledR}$ Silage F22 $\left(\right.$ Lactisil $^{\circledR} 200$ NB)-maitohappobakteeri- ja entsyymivalmisteella (Medipharm Ab). Herneen kukinta oli säilöttäessä päättynyt, palot olivat vihreitä ja pääosin jo turvonneita. Ohra oli taikinavaiheessa. Kasvuston kuiva-ainepitoisuus oli paalattaessa 20.6-24.3\%. Herneen osuus seoksen kuiva-aineesta oli $74 \%$ ja ohran $26 \%$. Kontrollirehuna oli esikuivattu (46 \%), pyöröpaaleihin säilötty (AIV2000-liuos, 5 1/tn) ensisadon timotei-nurminatasäilörehu.

Tutkimuksessa oli mukana kahdeksan vähintään kaksi kertaa poikinutta ay-lehmää. Lehmät jaettiin kahteen $4 \times 4$ latinalaiseen neliöön, joista neliön 1 lehmillä oli pötsifisteli. Jakson pituus oli 24 pv (ensimmäinen jakso $31 \mathrm{pv).} \mathrm{Syönti-} \mathrm{ja} \mathrm{tuotostiedot} \mathrm{on} \mathrm{laskettu} \mathrm{jokaisen} \mathrm{jakson} \mathrm{viimeiseltä}$ viikolta. Koetekijänä oli herne-ohrasäilörehun osuuden lisääntyminen $(0,33,67$ tai $100 \%$ karkearehun kuiva-aineesta) nurmisäilörehun osuuden vastaavasti vähentyessä. Lehmät saivat säilörehua vapaasti. Säilörehu jaettiin kolmessa erässä. Väkirehuna oli vilja-rypsipohjainen perustäysrehu (rv 192, NDF 284, sokerit 89 ja tärkkelys $325 \mathrm{~g} / \mathrm{kg} \mathrm{KA}$ ), jota neliön 1 lehmät saivat 12 $\mathrm{kg} / \mathrm{pv}$ ja neliön 2 lehmät $14.5 \mathrm{~kg} / \mathrm{pv}$ koko kokeen ajan. Väkirehu jaettiin kuudessa erässä. Rehun syönnin määrittämiseksi rehut ja rehujätteet punnittiin päivittäin. Kaikista paaleista määritettiin avattaessa kuiva-ainepitoisuus ja $\mathrm{pH}$. Jokaisen jakson lopussa säilörehuista kerättiin viikon ajan näytettä rehunpunnitusten yhteydessä kuiva-aine-, $\mathrm{pH}-$, rehu- ja erikoisanalyysiä varten sekä jäterehuista kuiva-aineen määrittämistä varten. Säilörehujen D-arvo laskettiin sellulaasiliukoisuuden perusteella (Friedel 1990). Väkirehusta kerättiin näytettä jokaisesta säkistä ja kuiva-aine tehtiin jaksoittain. Kokeen lopussa eri jaksojen näytteet yhdistettiin koko koeaikaa edustavaksi näytteeksi rehuanalyysiä varten.

Maitotuotos mitattiin päivittäin. Kunkin jakson lopussa maidosta otettiin näyte 4 viimeiseltä lypsykerralta. Yhdistetystä näytteestä määritettiin Valion Lapinlahden aluelaboratoriossa rasva-, valkuais-, laktoosi- ja ureapitoisuus (MilkoScan FT6000) ja soluluku (Fossomatic 5000). Neliön 2 lehmiltä pakastettiin myös näyte rasvahappomääritystä varten. Lisäksi jokaisen jakson lopussa neliön 2 lehmien yhden lypsykerran maidosta vietiin näyte EELA:an aistinvaraista laadunarviointia (maku, haju) varten.

Lehmät punnittiin kokeen alussa ja jokaisen jakson lopussa 2 peräkkäisenä päivänä. Neliön 1 lehmille tehtiin pötsintyhjennys kahtena päivänä jokaisen jakson lopussa (tuloksia ei esitetä tässä). Pötsintyhjennysten välisenä päivänä kerättiin pötsinestettä ennen aamuruokintaa sekä 1, 2, 3, 4, 6, 8 ja 10 tuntia aamuruokinnasta. Pötsinesteen $\mathrm{pH}$ ja $\mathrm{NH}_{4}-\mathrm{N}$-pitoisuus määritettiin heti, lisäksi otettiin näyte VFA-analyysiä varten. Rehun sulavuuden määrittämiseksi lehmiltä kerättiin jokaisen jakson lopussa sontaa viitenä peräkkäisenä päivänä kâksi kertaa päivässä. Näytteet pakastettiin ja keruujakson 
jälkeen ne sulatettiin, sekoitettiin ja otettiin kuiva-aine- ja rehuanalyysinäyte sekä näyte typpipitoisuuden määritystä varten. Typpimääritys tehtiin heti. Lisäksi neliön 2 lehmiltä kerättiin virtsaa kokonaiskeruuna jokaisen jakson lopussa 4 päivän ajan.

\section{Tulokset ja tulosten tarkastelu}

\section{Rehujen kemiallinen koostumus ja säilöntälaatu}

Herne-ohrasäilörehujen säilöntälaatu oli jaksojen lopussa kerättyjen näytteiden perusteella hyvä (taulukko 1). Kokeen aikana avatuista muurahaishapposäilötyistä paaleista pilaantuneita oli aistinvaraisesti arvioituna (haju, ulkonäkö) neljä ja ympillä säilötyistä kaksi. Osa pilaantumisista todennäköisesti aiheutui muoviin tulleista rei'istä. Voihappoa rehuissa ei ollut. Herne-ohrasäilörehu sisälsi raakavalkuaista keskimäärin $29 \%$ enemmän ja NDF-kuitua $33 \%$ vähemmän kuin nurmisäilörehu. Ammoniumtypen määrä oli myös herne-ohrasäilörehussa säilöntäaineen sisältämä ammoniakki huomioituna KTTK:n (1998) hyvälaatuisesta säilörehusta antamien laatuvaatimusten mukainen maitohappobakteeri-entsyymiseoksella säilöttyä rehua lukuunottamatta. Herneohrakasvuston puskurikapasiteetti säilöttäessä oli 79.3 ja nurmen $60.1 \mathrm{~g}$ maitohappoa/kg KA.

Taulukko 1. Säilörehun kuiva-aine-, raakavalkuais- ja NDF-pitoisuus ja säilönnällinen laatu.

\begin{tabular}{lcc|cccccc|cr}
\hline & $\begin{array}{c}\text { Ka- } \\
\%\end{array}$ & pH & $\begin{array}{l}\text { Raaka- } \\
\text { valk. }\end{array}$ & NDF & Sokerit & $\begin{array}{l}\text { Maito- } \\
\text { happo }\end{array}$ & $\begin{array}{l}\text { Etikka- } \\
\text { happo }\end{array}$ & $\begin{array}{l}\text { Voi- } \\
\text { happo }\end{array}$ & \multicolumn{2}{c}{$\begin{array}{c}\text { Liuk. Nonaistypestä } \\
\mathrm{NH}_{3}-\mathrm{N}^{*}\end{array}$} \\
\hline H-O, jakso 1 & 28.1 & 4.13 & 177 & 410 & 51 & 97 & 15 & 0.20 & 74 & $11.6 / 7.7$ \\
H-O, jakso 2 & 29.0 & 3.60 & 167 & 432 & 16 & 101 & 16 & 0.17 & 65 & $9.7^{* *}$ \\
H-O, jakso 3 & 22.8 & 4.11 & 169 & 411 & 33 & 95 & 11 & 0.13 & 72 & $9.4 / 4.8$ \\
H-O, jakso 4 & 25.2 & 3.98 & 168 & 420 & 22 & 124 & 17 & 0.12 & 90 & $12.5 / 7.8$ \\
N, jakso 1 & 49.1 & 5.29 & 139 & 549 & 123 & 9 & 5 & 0.16 & 61 & $4.1 / 1.4$ \\
N, jakso 2 & 57.0 & 4.86 & 132 & 563 & 132 & 4 & 5 & 0.18 & 49 & $1.6 / 1.6$ \\
N, jakso 3 & 60.9 & 5.36 & 137 & 548 & 142 & 3 & 6 & 0.16 & 45 & $2.8 / 0.8$ \\
N, jakso 4 & 56.5 & 5.11 & 118 & 569 & 161 & 4 & 6 & 0.21 & 51 & $3.9 / 1.5$ \\
\hline
\end{tabular}

$\mathrm{H}-\mathrm{O}=$ herne-ohrasäilörehu, $\mathrm{N}=$ nurmisäilörehu, ${ }^{*} \mathrm{NH}_{3}-\mathrm{N}$ yht. $/ \mathrm{NH}_{3}-\mathrm{N}$ yht.-arvioitu säilöntäaineesta tullut $\mathrm{NH}_{3}-\mathrm{N}$

**maitohappobakteeri- ja entsyymivalmisteella säilötty rehu

\section{Rehun syönti, maitotuotos ja maidon koostumus}

Tuloksia laskettaessa kolmannelta jaksolta poistettiin yhden lehmän tiedot utaretulehduksesta aiheutuneen tuotoksen laskun vuoksi. Sama lehmä poistettiin neljännellä jaksolla kokonaan kokeesta fistelin jatkuvasti irrotessa. Neljänneltä jaksolta kokeesta poistettiin myös toinen lehmä huonon utareterveyden aiheuttaman heikon tuotoksen vuoksi.

Lehmät söivät eniten $33 \%$ herne-ohrasäilörehua sisältänyttä seosta ja vähiten puhdasta herneohrasäilörehua (taulukko 2). Herne-ohrasäilörehun osuuden lisääminen laski syöntiä lineaarisesti $(\mathrm{p}<0.01)$. Väkirehun syönnissä ei ollut eroa. Eniten lypsivät puhdasta herne-ohrasäilörehua saaneet lehmät. Tuotos lisääntyi lineaarisesti merkitsevästi $(\mathrm{p}<0.05)$ herne-ohrasäilörehun osuuden seoksesta kasvaessa. Herneen osuuden lisääntyessä maidon rasva- ja valkuaispitoisuus laskivat (taulukko 2), joista vaikutus valkuaispitoisuuteen oli lineaarinen $(p<0.05)$. Rasva- ja valkuaistuotoksessa ei ollut eroa ruokintojen välillä. Linolihapon määrä maidossa lisääntyi $(p<0.05)$ herneen osuuden kasvaessa. Myös maidon ureapitoisuus nousi $(\mathrm{p}<0.01)$ herneen osuuden lisääntyessä. Maidon aistinvaraiseen laatuun (haju, maku) hernesäilörehuruokinta ei vaikuttanut.

Herne-ohrasäilörehun syönti oli odotettua pienempi ja syöntimäärissä oli suurta vaihtelua eri lehmien välillä. Lehmät söivät puhdasta herne-ohrasäilörehua keskimäärin $4.4-10.6 \mathrm{~kg} \mathrm{KA} / \mathrm{pv}$. Joissakin tutkimuksissa (Adesogan ym. 2001, Salawu ym. 2002) karkearehun syönti on lisääntynyt merkitsevästi, kun lehmiä on nurmisäilörehun sijaan ruokittu herne-vehnäsäilörehulla. Lisääntyneestä kuiva-aineen syönnistä huolimatta herne-vehnäsäilörehuruokinta ei aina ole lisännyt maitotuotosta. Adesogan ym. (2001) kokeessa verrattiin kahta eri hernelajiketta sisältänyttä herne-vehnäsäilörehua ja nurmisäilörehua. Lyhytkortisesta lajikkeesta tehty säilörehu lisäsi merkitsevästi tuotosta 
Salawun ym. (2002) kokeessa myöhemmällä kasvuasteella korjattu herne-vehnäsäilörehu lisäsi tuotosta nurmisäilörehuun verrattuna keskimäärin $2.1 \mathrm{~kg} / \mathrm{pv}$ ja varhaisemmalla kasvuasteella korjattu rehu $1.1 \mathrm{~kg} / \mathrm{pv}$. Salawun ym. (2002) kokeessa maidon rasvapitoisuus aleni merkitsevästi hernevehnäsäilörehulla ruokittaessa. Adesogan ym. (2001) kokeessa maidon koostumuksessa ei ollut eroa herne-vehnäsäilörehu- ja nurmisäilörehuruokintojen välillä.

Taulukko 2. Rehun syönti, maitotuotos ja maidon koostumus.

\begin{tabular}{|c|c|c|c|c|c|c|c|c|}
\hline & \multicolumn{4}{|c|}{ Ruokinta } & & \multicolumn{3}{|c|}{ Tilastollinen merkitsevyys } \\
\hline & $\begin{array}{c}1 \\
(n=7)\end{array}$ & $\begin{array}{c}2 \\
(n=7)\end{array}$ & $\begin{array}{c}3 \\
(n=8)\end{array}$ & $\begin{array}{c}4 \\
(n=7)\end{array}$ & SEM & Ruokinta & Lin. & 2. ast. \\
\hline \multicolumn{9}{|l|}{ Syönti, kg KA/pv: } \\
\hline Säilörehu & 9.2 & 9.7 & 9.0 & 7.1 & 0.72 & $*$ & $* *$ & $*$ \\
\hline Väkirehu & 11.5 & 11.5 & 11.5 & 11.5 & 0.13 & & & \\
\hline Yht. & 20.8 & 21.1 & 20.4 & 18.5 & 0.70 & $* *$ & $* *$ & $*$ \\
\hline Maitotuotos, $\mathrm{kg} / \mathrm{pv}$ & 28.7 & 28.5 & 29.5 & 30.3 & 2.27 & o & $*$ & \\
\hline EKM, kg/pv & 30.3 & 29.8 & 30.3 & 31.3 & 2.05 & & & \\
\hline Rasva-\% & 4.13 & 4.14 & 4.06 & 4.04 & 0.16 & & & \\
\hline Valkuais-\% & 3.85 & 3.78 & 3.70 & 3.71 & 0.10 & & * & \\
\hline Laktoosi-\% & 4.75 & 4.76 & 4.73 & 4.74 & 0.10 & & & \\
\hline Rasvatuotos, g/pv & 1185 & 1165 & 1178 & 1216 & 70.8 & & & \\
\hline Valkuaistuotos, g/pv & 1099 & 1063 & 1083 & 1115 & 75.0 & & & o \\
\hline \multicolumn{9}{|l|}{ Rasvahapot: } \\
\hline C4-C14 yht. & 28.5 & 28.4 & 28.5 & 28.4 & 0.70 & & & \\
\hline $\mathrm{C} 18: 2$ & 2.06 & 2.19 & 2.22 & 2.45 & 0.139 & $*$ & $* *$ & \\
\hline $\mathrm{C} 18: 3$ & 0.58 & 0.56 & 0.52 & 0.55 & 0.040 & & & \\
\hline CLA9.11 & 0.46 & 0.44 & 0.48 & 0.51 & 0.026 & $*$ & $* *$ & o \\
\hline Urea (mg/l) & 21 & 23 & 24 & 26 & 1.3 & $* *$ & $* * *$ & \\
\hline Solut (lg) & 1.75 & 1.73 & 1.77 & 1.87 & 0.253 & & & \\
\hline
\end{tabular}

Ruokinta: $1=100 \%$ nurmisr.; $2=33 \%$ herne-ohrasr.:67 \% nurmisr.; $3=67 \%$ herne-ohrasr.:33 \% nurmisr.; $4=100 \%$ herne-ohrasr. Tilastollinen merkitsevyys: $* * *=p<0.001, * *=p<0.01, *=p<0.05, o=p<0.10$

\section{Rehun hyväksikäyttö ja pötsifermentaatio}

Orgaanisen aineen ja raakavalkuaisen sulavuudessa ei ollut eroa, mutta NDF:n sulavuus huonontui $(\mathrm{p}<0.05)$ herne-ohrasäilörehun osuuden kasvaessa (taulukko 3). Energiakorjattu maitotuotos syötyä kuiva-ainekiloa kohti oli korkein puhtaalla herne-ohrasäilörehulla ruokittaessa $(p<0.001)$. Lisäksi rehuvalkuaisen hyväksikäyttö oli puhtaalla nurmi- tai herne-ohrasäilörehulla ruokittaessa parempi kuin seosruokinnoilla. Energian hyväksikäytössä maidontuotantoon ei elopainon muutos huomioituna ollut eroa ruokintojen välillä.

Taulukko 3. Rehun hyväksikäyttö.

\begin{tabular}{|c|c|c|c|c|c|c|c|c|}
\hline & \multicolumn{4}{|c|}{ Ruokinta } & & \multicolumn{3}{|c|}{ Tilastollinen merkitsevyys } \\
\hline & $\begin{array}{c}1 \\
(n=7)\end{array}$ & $\begin{array}{c}2 \\
(\mathrm{n}=7)\end{array}$ & $\begin{array}{c}3 \\
(\mathrm{n}=8)\end{array}$ & $\begin{array}{c}4 \\
(n=7)\end{array}$ & SEM & Ruokinta & Lin. & 2. ast. \\
\hline Sulavuus, \%: & & & & & & & & \\
\hline Org. aine & 71.0 & 69.6 & 70.7 & 70.4 & 1.03 & & & \\
\hline Raakavalk. & 66.9 & 65.0 & 66.5 & 67.3 & 1.22 & & & \\
\hline $\mathrm{NDF}$ & 59.2 & 57.6 & 56.1 & 53.1 & 1.52 & $*$ & $* *$ & \\
\hline $\mathrm{EKM} \mathrm{kg/kg} \mathrm{KA}$ & 1.46 & 1.41 & 1.47 & 1.71 & 0.108 & $* * *$ & $* * *$ & $* *$ \\
\hline Maidon N/rehun N & 31.3 & 28.7 & 28.9 & 32.1 & 2.08 & $* *$ & & $* * *$ \\
\hline Elopaino, kg & 633 & 641 & 634 & 631 & 18.9 & & & \\
\hline Elop. muutos, kg & 0.58 & 0.49 & 0.46 & 0.10 & 0.239 & & & \\
\hline $\mathrm{ME}$ & 219 & 219 & 215 & 193 & 6.5 & $* *$ & $* *$ & $*$ \\
\hline $\mathrm{k}_{1}$ & 0.61 & 0.60 & 0.62 & 0.75 & 0.05 & $* *$ & $* * *$ & $* *$ \\
\hline $\mathrm{k}_{\mathrm{lepm}}$ & 0.73 & 0.67 & 0.71 & 0.79 & 0.04 & & & o \\
\hline
\end{tabular}

Merkkien selitykset ks. taulukko 2

Herne-ohrasäilörehu nosti pötsin $\mathrm{pH}$ :ta ja $\mathrm{NH}_{4}-\mathrm{N}$-pitoisuutta (taulukko 4), mutta ero ruokintojen välillä ei ollut merkitsevä. Haihtuvista rasvahapoista etikkahapon osuus väheni $(p<0.05)$ ja 
isovoihapon $(\mathrm{p}<0.01)$ sekä isovaleriaanahapon $(\mathrm{p}<0.5)$ osuus lisääntyi herne-ohrasäilörehun osuuden kasvaessa.

Taulukko 4. Pötsifermentaatio.

\begin{tabular}{|c|c|c|c|c|c|c|c|c|c|}
\hline & \multicolumn{4}{|c|}{ Ruokinta } & & \multicolumn{4}{|c|}{ Tilastollinen merkitsevyys } \\
\hline & 1 & 2 & 3 & 4 & SEM & Ruokinta & Lin. & 2.ast. & 3.ast. \\
\hline $\mathrm{pH}$ & 6.17 & 6.18 & 6.34 & 6.40 & 0.075 & & 0 & & \\
\hline $\mathrm{NH}_{4}-\mathrm{N}, \mathrm{mg} / 100 \mathrm{ml}$ & 6.6 & 9.8 & 10.9 & 13.1 & 1.71 & & o & & \\
\hline $\begin{array}{l}\text { Vfa yht., mol/l } \\
\mathrm{mmol} / \mathrm{mol}:\end{array}$ & 120 & 123 & 116 & 116 & 2.6 & & & & \\
\hline Etikkah. & 644 & 637 & 639 & 619 & 3.5 & $*$ & $\mathrm{O}$ & o & $\mathrm{o}$ \\
\hline Prop.h. & 208 & 213 & 203 & 216 & 3.8 & & & & $\mathrm{o}$ \\
\hline Voih. & 115 & 113 & 116 & 119 & 2.2 & & & & \\
\hline Isovoih. & 6.2 & 7.4 & 8.3 & 10.2 & 0.30 & $* *$ & $* *$ & & \\
\hline Isoval.h. & 7.6 & 10.5 & 11.5 & 14.4 & 0.73 & $*$ & $* *$ & & \\
\hline Val.h. & 15.1 & 15.1 & 15.4 & 16.4 & 0.26 & o & & o & \\
\hline Kapr.h. & 4.6 & 4.8 & 6.0 & 5.3 & 0.35 & & $*$ & & \\
\hline Eh./Prop.h. & 3.11 & 3.02 & 3.17 & 2.90 & 0.058 & o & & & $*$ \\
\hline (Eh.+Vh.)/Prop.h. & 3.67 & 3.56 & 3.75 & 3.46 & 0.071 & & & & o \\
\hline Ngr* & 4.00 & 3.88 & 4.09 & 3.80 & 0.075 & & & & o \\
\hline
\end{tabular}

$* \mathrm{Ngr}=$ non glugogenic ratio (etikkah. $+2 \times$ voih.+val.)/(proph.+val.), muut merkit ks. taulukko 2

\section{Johtopäätökset}

Tämän tutkimuksen mukaan herneen ja ohran seoskasvustosta tehty säilörehu sopii hyvin lypsylehmien ruokintaan. Vaikka lehmät söivät puhdasta herne-ohrasäilörehua vähemmän kuin nurmisäilörehua, maitotuotos lisääntyi lineaarisesti herneen osuuden lisääntyessä. Lisäksi puhdasta herne-ohrasäilörehua syöneiden lehmien energiakorjattu maitotuotos syötyä kuiva-ainekiloa kohti oli korkein. Maidon rasvapitoisuudessa ei ollut merkitsevää eroa eri karkearehujen välillä, mutta valkuaispitoisuus laski lineaarisesti herneen osuuden lisääntyessä. Maidon hajuun tai makuun hernesäilörehuruokinta ei vaikuttanut.

Säilöntä kannattaa aloittaa ennen herneen tuleentumista viljan ollessa taikinavaiheessa. Herne-viljaseoksesta saadaan yhdellä niittokerralla korjattua korkea kuiva-ainesato. Kuiva-ainesadon määrää pienentävät kuitenkin korjuuvaiheessa tapahtuvat tappiot. Korjuutappioita aiheuttivat tässäkin kokeessa lakoutunut kasvusto sekä niiton ja paalauksen aikana tapahtunut tähkien ja palkojen variseminen. Lakoutumista voidaan vähentää viljemällä enintään puolikorkeita hernelajikkeita ja valitsemalla sopiva tukikasvi. Myös kylvöseoksen siemensuhteella on vaikutusta. Varisemistappiota voidaan pienentää kiinnittämällä huomiota korjuussa käytettävään koneistukseen ja koneiden säätöihin. Mitä vähemmän kasvustoa joudutaan käsittelemään, sitä pienempi on varisemistappio. Säilöntätuloksen varmistamiseksi säilöntäaineen käyttö on suositeltavaa. Hyvälaatuista rehua voidaan saada sekä muurahaishappopohjaisella että maitohappobakteeriymppiä sisältävällä säilöntäaineella. Muurahaishappo estää kuitenkin ymppiä tehokkaammin valkuaisen hajoamista rehussa, millä on merkitystä erityisesti palkoviljan osuuden ollessa suuri. Säilöntäaineen lisäksi myös esikuivaus parantanee säilöntälaatua.

\section{Kirjallisuus}

Adesogan, A.T., Salawu, M.B. \& Dewhurst, R.J. 2001. The effect of replacing grass silage with pea/wheat bicrops in dairy cow diets on feed intake, concentrate utilization and milk production. Proceedings of the British Society of Animal Science in Winter Meeting, Scarborough. p. 3.

Friedel, K.1990. Die Schätzung des energetischen Futterwertes von Grobfutter mit Hilfe einer Cellulasemethode. Wiss. Z. Univ. Rostock, N-Reihe 39, 8:78-86.

KTTK 1998. Kasvintuotannon tarkastuskeskus/maatalouskemian osasto. Tiedote 7.

Mustafa, A.F., Christensen, D.A. \& McKinnon, J.J.2000. Effects of pea, barley and alfalfa silage on ruminal nutrient degradability and performance of dairy cows. Journal of Dairy Science 83:2859-2865.

Salawu, M.B., Adesogan, A.T. \& Dewhurst, R.J. 2002. Forage intake, meal patterns and milk production of lactating dairy cows fed grass silage of pea-wheat bi-crop silages. Journal of Dairy Science 85:3035-3044. 